\title{
BODY-WAVE AMPLITUDE AND TRAVEL-TIME CORRELATIONS ACROSS NORTH AMERICA
}

\author{
By Thorne Lay and Donald V. Helmberger
}

\begin{abstract}
Relationships between travel-time and amplitude station anomalies are examined for short- and long-period SH waves and short-period $P$ waves recorded at North American WWSSN and Canadian Seismic Network stations. Data for two azimuths of approach to North America are analyzed. To facilitate intercomparison of the data, the $S$-wave travel times and amplitudes are measured from the same records, and the amplitude data processing is similar for both $P$ and $S$ waves. Short-period $\mathbf{P}$ - and $\mathbf{S}$-wave amplitudes have similar regional variations, being relatively low in the western tectonic region and enhanced in the shield and mid-continental regions. The east coast has intermediate amplitude anomalies and systematic, large azimuthal travel-time variations. There is a general correlation between diminished short-period amplitudes and late $S$-wave arrival times, and enhanced amplitudes and early arrivals. However, this correlation is not obvious within the eastern and western provinces separately, and the data are consistent with a step-like shift in amplitude level across the Rocky Mountain front. Long-period $\mathbf{S}$ waves show no overall correlation between amplitude and travel-time anomalies.
\end{abstract}

\section{INTRODUCTION}

It has long been indicated that there is a general association between $P$-wave amplitude and travel-time anomalies across North America (Herrin and Taggart, 1962; Romney et al., 1962). $P$ - and $S$-wave amplitude and travel-time station anomalies show similar regional variations with diminished amplitudes and late arrival times in the Basin and Range and Rocky Mountain provinces, and enhanced amplitudes and early arrivals in the Great Plains and shield areas (e.g., Cleary, 1967; Evernden and Clark, 1970; Sengupta, 1975; North, 1977). However, this correlation is not a simple one, even for the few studies which measure the amplitudes and travel times from the same data (Cleary, 1967; Sengupta, 1975), and does not appear to exist on a global basis (Shore, 1982).

The North American observations are usually attributed to coupled lateral variations in the upper mantle low velocity and low $Q$ zones between western and eastern North America (e.g., Hales et al., 1968; Hales and Herrin, 1972), although it is only relatively recently that actual measurements of lateral variations in attenuation have been shown to correlate with amplitude anomalies (Der and McElfresh, 1977; Der et al., 1979, 1982; Lay and Helmberger, 1981). These studies have shown that there is a regional variation in attenuation associated with a baseline shift in amplitude levels between the two major provinces, but a large amount of amplitude variation within each region is not correlated with attenuation differences.

In this paper, we attempt to quantify the degree of correlation between bodywave amplitude and travel-time variations across North America for short- and long-period $S H$ and short-period $P$ phases. Where possible, the amplitude and travel-time measurements are made from the same records, and the method of amplitude analysis is the same for all observations, which allows us to more confidently compare the station anomalies than previous work. Data from two azimuths are processed and compared separately to avoid averaging out subtle trends. 


\section{Amplitude and Travel-Time Data}

The S-wave travel-time and amplitude observations presented here were recorded at North American WWSSN and Canadian Seismic Network stations. Seventeen moderate size $\left(m_{b}=5.5\right.$ to 6.0$)$ intermediate and deep focus earthquakes in Argentina and the Sea of Okhotsk were selected for analysis on the basis of their simple, impulsive waveforms and stable $S H$ radiation patterns to North America. The station and event epicenter locations are shown in Figure 1. The short- and longperiod horizontal components in the distance range $40^{\circ}$ to $80^{\circ}$ were digitized and
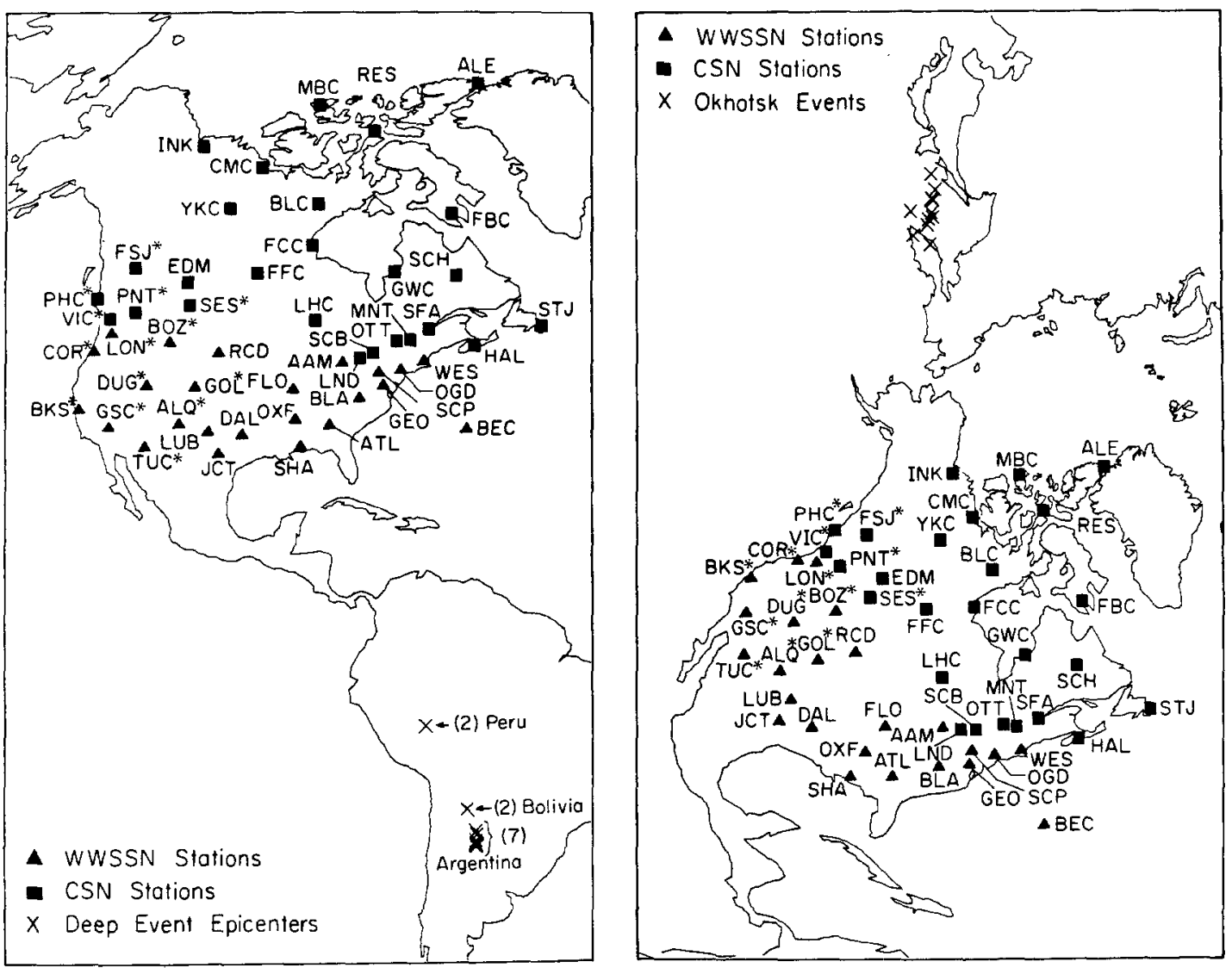

Fig. 1. Azimuthal equidistance projections centered on the Argentine (left) and Sea of Okhotsk (right) source regions. The locations of the intermediate and deep focus event epicenters and recording stations used in this study are shown. The stations with an asterisk are designated as stations within the western tectonic province. GSC, RCD, and SCH are approximately $80^{\circ}$ from the Argentine source region. SHA ranges from $78^{\circ}$ to $88^{\circ}$ from the Sea of Okhotsk events used.

rotated into transverse and radial polarizations, and amplitude and travel-time measurements were made for the $S H$ components. The first peak-to-first trough and first peak amplitudes were measured for the short- and long-period signals, respectively. Figure 2 shows representative $S H$ waveforms for one of the Argentine events. The travel times and amplitudes of these simple phases can be reliably measured. Radiation pattern corrections were determined from focal mechanisms constrained by $P$-wave first motions, $S$-wave polarizations, and long-period $S V / S H$ amplitude ratios, and these corrections were applied to the amplitude data along with instrument gain and geometric spreading corrections. Station anomalies were 
then determined by removing relative event-size factors (for amplitudes) and baseline shifts in the Jeffreys-Bullen residuals (for travel times) using the procedures described in Lay and Helmberger (1981) and Lay (1983). The data for the two source regions were processed separately.

A similar set of short-period $P$-wave amplitudes has been presented by Butler and Ruff (1980) and extended by Butler et al. (1979). Earthquakes in South America and in source regions to the northwest of North America, as well as Russian nuclear explosions at five test sites, were used to determine relative $P$-wave amplitude patterns for three azimuths to North American WWSSN stations. The data were

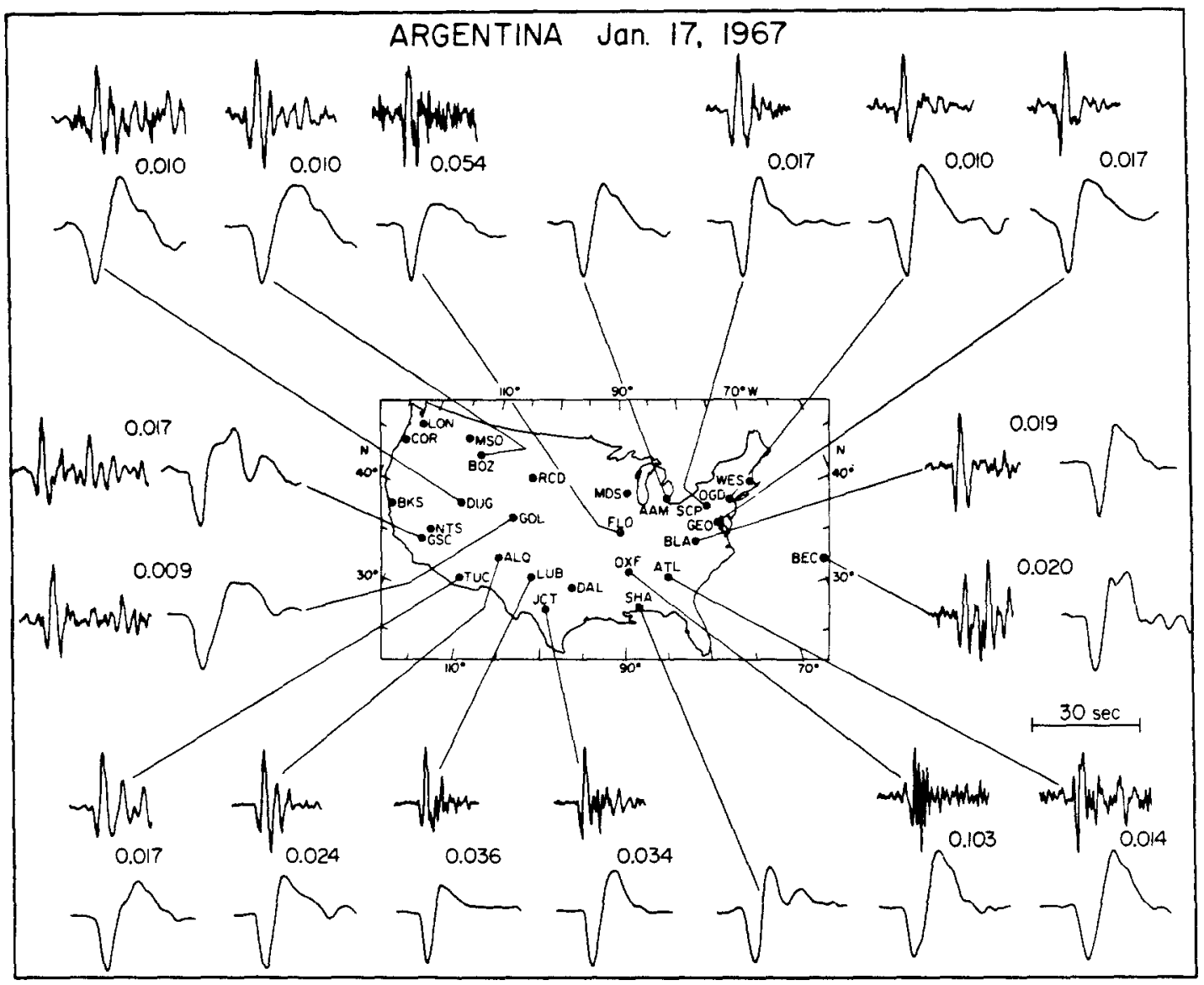

FIg. 2. Short- and long-period $S H$ components and amplitude ratios of the Argentine event of 17 January 1967 recorded at North American WWSSN stations.

selected, measured, and processed in a manner similar to that used in the $S$-wave analysis, although radiation pattern corrections were not applied to the earthquake data. The stability of the relative amplitude behavior between events and the coherence of the waveforms for each event indicate that the source radiation corrections are small for the narrow azimuth range spanned by the receivers, as was found for the $S$ waves. The corresponding $P$-wave travel times were not measured, but a recent study by Dziewonski and Anderson (1983) provides the most reliable azimuthally dependent $P$-wave travel-time station anomalies for North America presently available. The processing and quantity of data in that study were signifi- 
cantly different than for the other data sets, but it is of interest to compare the azimuthally dependent $S$ - and $P$-wave station travel-time anomalies.

\section{Comparison of North American Station Anomalies}

The Argentine and Sea of Okhotsk $S$-wave travel-time and short-period amplitude anomalies are shown in Figure 3 and tabulated in Table 1. The travel-time residuals were determined using the short- and long-period data combined (see Lay, 1983, for
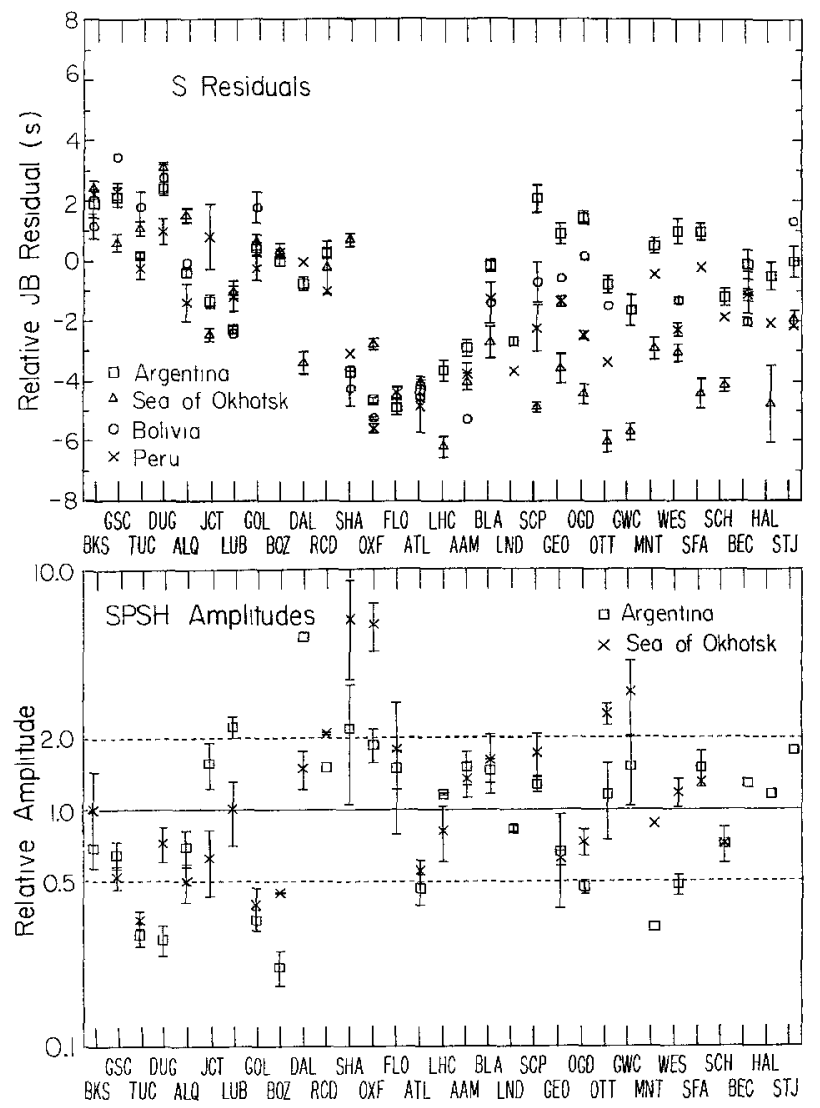

FIG. 3. (Top) The mean and standard error of the mean of the $S$-wave JB residuals at North American stations for the Sea of Okhotsk and South American source regions. Only those stations at which anomalies could be determined for both azimuths are shown. Source region baseline corrections have been determined using the first 11 stations from the left. (Bottom) Comparison of the station amplitude anomalies from the Sea of Okhotsk and Argentina short-period SH data. The relative amplitudes have been adjusted to minimize the scatter at each station following the procedure described in Lay and Helmberger (1981).

procedure) because the relative residuals are not frequency dependent. $S$-wave station travel-time anomalies for the Bolivian and Peruvian source regions are also shown in Figure 3. The amplitudes for these events were not measured because the signals are complicated and dominated by $S V$ radiation. In the top figure, the traveltime anomaly patterns for each source region have been baseline shifted to minimize the scatter at the first 11 stations from the left, which are western and Texas stations. These small shifts were applied in order to simplify comparison of the relative patterns across North America observed for each source region. The stations 
TABLE 1

Argentine and Sea of Okhotsk $S$-Wave Travel-time and Short-Period Amplitude ANOMALIES

\begin{tabular}{|c|c|c|c|c|c|c|c|}
\hline \multirow{2}{*}{ Station } & \multicolumn{3}{|c|}{ Sea of Okhotsk } & \multicolumn{3}{|c|}{ Argentina } & \multirow{2}{*}{ Direction } \\
\hline & $A_{S P S}$ & $\boldsymbol{A}_{L P S}$ & $T_{s}$ & $A_{S P S}$ & $\boldsymbol{A}_{L P S}$ & $T_{S}$ & \\
\hline AAM & 0.63 & 0.50 & -2.87 & 0.69 & 0.53 & -1.86 & $\mathbf{E}$ \\
\hline ALE & 0.77 & 0.63 & -2.28 & - & - & - & $\mathbf{E}$ \\
\hline ALQ & 0.26 & 0.60 & 2.81 & 0.32 & 0.40 & 0.62 & W \\
\hline ATL & 0.28 & 0.45 & -2.71 & 0.22 & 0.39 & -3.29 & $\mathbf{E}$ \\
\hline $\mathrm{BEC}$ & - & - & - & 0.59 & 0.54 & 0.87 & $\mathbf{E}$ \\
\hline BKS & 0.38 & 0.61 & 3.62 & 0.32 & 0.63 & 2.91 & W \\
\hline BLA & 0.73 & 0.64 & -1.23 & 0.67 & 0.64 & 0.85 & $\mathbf{E}$ \\
\hline BLC & - & 0.67 & -3.04 & - & - & - & $\mathbf{E}$ \\
\hline $\mathrm{BOZ}$ & 0.18 & 0.61 & 1.50 & 0.10 & 0.29 & 1.00 & W \\
\hline $\mathrm{CMC}$ & 1.19 & 1.30 & -1.31 & - & - & - & $\mathrm{E}$ \\
\hline COR & 0.38 & 0.54 & 3.36 & - & - & - & W \\
\hline DAL & 0.66 & 0.40 & -1.98 & 2.43 & 0.79 & $0.26^{*}$ & $\mathbf{E}$ \\
\hline DUG & 0.33 & 0.61 & 4.36 & 0.13 & 0.46 & 3.39 & W \\
\hline EDM & 0.63 & 0.71 & -0.88 & - & - & - & $\mathbf{E}$ \\
\hline FBC & 0.51 & 0.55 & -5.43 & - & - & - & $\mathrm{E}$ \\
\hline $\mathrm{FCC}$ & 0.93 & 0.72 & -1.62 & - & - & - & $\mathbf{E}$ \\
\hline $\mathrm{FFC}$ & 1.04 & 0.65 & -0.10 & - & - & - & $\mathbf{E}$ \\
\hline FLO & 0.79 & 0.51 & -3.26 & 0.69 & 0.24 & $-3.81^{*}$ & $\mathrm{E}$ \\
\hline FSJ & 0.96 & 0.65 & 2.58 & - & - & - & W \\
\hline GEO & 0.29 & 0.53 & -2.33 & 0.31 & 0.64 & $1.89^{*}$ & $\mathrm{E}$ \\
\hline GOL & 0.18 & 0.47 & 1.92 & 0.16 & 0.46 & 1.41 & W \\
\hline GSC & 0.22 & 0.47 & 1.78 & 0.30 & 0.46 & 3.12 & W \\
\hline GWC & 1.31 & 0.73 & -4.19 & 0.70 & - & $-0.62^{*}$ & $\mathrm{E}$ \\
\hline HAL & - & 0.39 & -1.91 & 0.53 & 0.81 & $0.50^{*}$ & $\mathbf{E}$ \\
\hline INK & - & 0.71 & -1.61 & - & - & - & $\mathbf{E}$ \\
\hline JCT & 0.34 & 0.51 & -1.12 & 0.72 & 0.54 & -0.34 & $\mathrm{E}$ \\
\hline LHC & 0.37 & 0.49 & -4.80 & 0.54 & 0.50 & -2.61 & $\mathrm{E}$ \\
\hline LND & - & - & - & 0.39 & 1.42 & -1.64 & $\mathbf{E}$ \\
\hline LON & 0.09 & 0.56 & 0.77 & - & - & - & W \\
\hline LUB & 0.40 & 0.57 & 0.26 & 1.03 & 0.59 & -1.26 & $\mathrm{E}$ \\
\hline MBC & 0.76 & 0.73 & -1.00 & - & - & - & $\mathbf{E}$ \\
\hline MNT & 0.36 & 0.79 & -1.62 & 0.15 & 0.23 & $1.49^{*}$ & $\mathbf{E}$ \\
\hline OGD & 0.34 & 0.37 & -3.12 & 0.22 & 0.61 & $2.40^{*}$ & E \\
\hline OTT & 1.06 & 0.54 & -4.61 & 0.53 & 0.49 & $0.24^{*}$ & $\mathrm{E}$ \\
\hline OXF & 2.69 & 0.55 & -1.42 & 0.86 & 0.32 & $-3.59^{*}$ & $\mathbf{E}$ \\
\hline PHC & - & 0.56 & 2.16 & - & - & - & W \\
\hline PNT & - & 0.56 & -0.53 & - & - & - & W \\
\hline $\mathrm{RCD}$ & 1.15 & 0.70 & 1.21 & 0.69 & 0.36 & 1.26 & $\mathbf{E}$ \\
\hline RES & 0.41 & 0.76 & -0.23 & - & - & - & $\mathbf{E}$ \\
\hline $\mathrm{SCB}$ & - & 0.60 & -4.66 & - & - & - & $\mathrm{E}$ \\
\hline $\mathrm{SCH}$ & 0.36 & 0.44 & -2.40 & 0.33 & 0.52 & $-0.20^{*}$ & $\mathrm{E}$ \\
\hline $\mathrm{SCP}$ & 0.75 & 0.45 & -3.44 & 0.59 & 0.85 & $3.06^{*}$ & $\mathbf{E}$ \\
\hline SES & 0.90 & 0.75 & 2.80 & - & - & - & W \\
\hline SFA & 0.79 & 0.55 & -2.69 & 0.69 & 0.71 & $1.95^{*}$ & $\mathbf{E}$ \\
\hline SHA & 2.39 & 0.97 & 2.00 & 1.01 & 0.61 & $-2.64^{*}$ & $\mathrm{E}$ \\
\hline STJ & - & 0.76 & -0.54 & 0.81 & 0.79 & $0.97^{*}$ & $\mathrm{E}$ \\
\hline TUC & 0.17 & 0.39 & 2.42 & 0.14 & 0.28 & 1.17 & W \\
\hline VIC & 0.46 & 0.49 & 1.38 & - & - & - & W \\
\hline WES & 0.54 & 0.53 & -1.72 & 0.22 & 0.36 & $1.97^{*}$ & $\mathbf{E}$ \\
\hline YKC & 0.45 & 0.59 & -1.64 & - & - & - & $\mathrm{E}$ \\
\hline
\end{tabular}

* Argentine data with anomalous travel times. 
are ordered in azimuth from the Argentine source region, and only those stations at which anomalies could be determined from both azimuths are shown.

Figure 3 demonstrates that the $S H$ travel times are relatively late (positive) and the amplitudes are relatively low at western stations for both azimuths. The central United States stations record arrivals 4 to $5 \mathrm{sec}$ earlier than do the western stations, and the amplitudes are 4 to 5 times larger as well. The east coast stations record intermediate amplitudes and show the clearest evidence for azimuthal variations in travel-time anomalies. Relative to the central and western stations, the east coast stations record early arrivals from the Sea of Okhotsk and late arrivals from Argentina. Other South American source regions show relatively earlier arrivals in the east coast than observed for Argentina. This indicates that significant nearsource or deep mantle velocity structure affects the relative travel-time pattern from Argentina. This is discussed in greater detail below and by Lay (1983), who concludes that the Argentine signals recorded in the east coast are anomalously late because

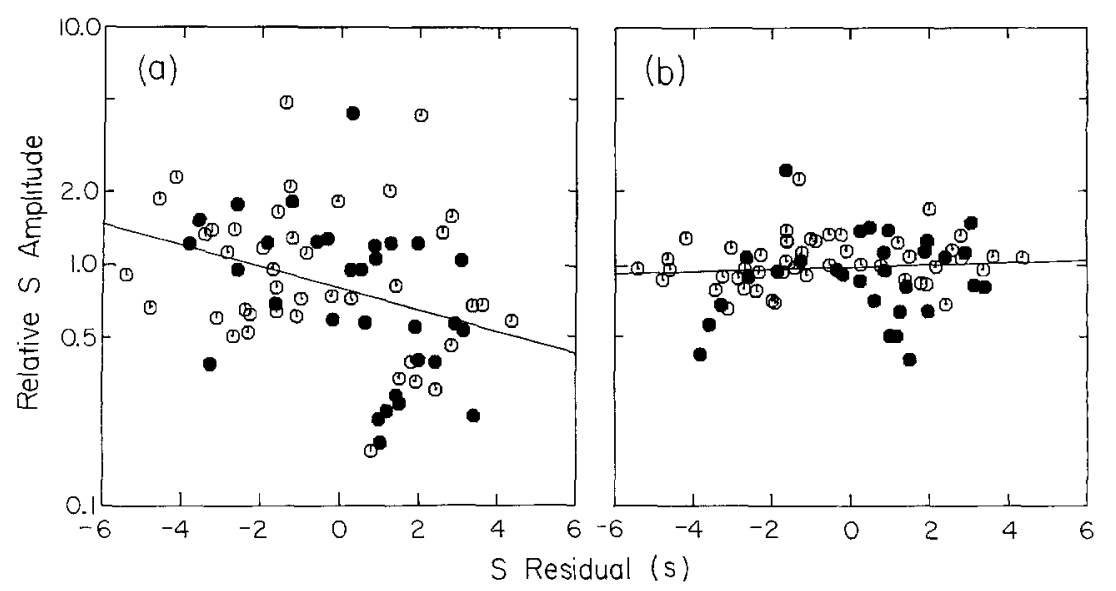

FIG. 4. (a) Comparison of short-period $S$-wave amplitude anomalies and station $S$-wave residuals in North America for the Sea of Okhotsk (open symbols) and Argentina (filled symbols) source regions. (b) A similar comparison for long-period $S$-wave amplitude anomalies and $S$ residuals. The curves are major axis regressions assuming equal weighting.

they encounter a localized low-velocity region in the lower mantle. Some of the azimuthal variation observed at east coast stations may also be due to strong lateral gradients in upper mantle shear velocity structure, with the velocity increasing toward the Canadian shield. The short-period $S H$ amplitudes do not show similar azimuthal variations.

In Figure 4, the $S$-wave amplitude and travel-time anomalies for both source regions are compared. All of the available determinations are included, with the solid symbols indicating Argentine observations. The general features are similar for both azimuths, although the long-period amplitudes from Argentina have more scatter than observed for the Sea of Okhotsk data. The short-period amplitude anomalies clearly have a much greater range in variation than do the long periods, as has been observed for $P$ waves (Booth et al., 1974; Sengupta, 1975). The short periods also show a tendency for late arrivals (positive residuals) to be low amplitude, which is not apparent in the long periods. Booth et al. (1974) found little correlation between short- and long-period $P$-wave amplitude variations, and argued that this supports the interpretation that the short-period amplitude variations are due to $Q$ variations. 
Using the major axis regression described by York (1966), relations between the logarithms of the short-period $S$-wave amplitudes $\left(A_{S P S}\right)$ and long-period $S$-wave amplitudes $\left(A_{L P S}\right)$, and the $S$-wave travel-time anomalies $\left(T_{S}\right)$ have been determined. The relations found for equal weighting of each data point and using all of the data are indicated in Figure 4 and given by

$$
\begin{aligned}
& \log A_{S P S}=-0.340( \pm 0.035)-0.047( \pm 0.015) T_{S} \\
& \log A_{L P S}=-0.256( \pm 0.016)+0.004( \pm 0.007) T_{S}
\end{aligned}
$$

The intercept values are not significant due to the arbitrary baselines in both parameters. There is a weak, resolvable correlation between the log of the shortperiod amplitudes and the travel-time anomalies, with a linear correlation coefficient, $r$, of -0.341 , but the long-period amplitudes do not show similar behavior, as the correlation coefficient is 0.077 . More sophisticated weighting schemes can be employed, but the errors involved in amplitude and travel-time measurements are quite different in nature, and rigorous statistics may not be useful. The regressions presented here are intended only to indicate the relative degree of correlation between parameters.

In a detailed investigation of $S$ and $S c S-S$ travel-time anomalies for deep South American and Sea of Okhotsk events recorded in North America, Lay (1983) concluded that the Argentine $S$-wave data is contaminated by lower mantle anomalies. Large, localized velocity anomalies are observed at east coast and Mississippi Valley stations. As seen in Figure 3, these stations show strong azimuthal variations in $S$ residuals as well as distance dependence of $S$ residuals between source regions in Peru, Bolivia, and Argentina. The travel-time anomalies are as much as $5 \mathrm{sec}$ and are not apparent in the $S c S$ arrivals from the same events, which suggest a lower mantle origin. The greater range in long-period amplitude anomalies for the Argentine data appears to be associated with these travel-time anomalies as well. To ensure that these strong anomalies do not dominate the patterns in Figure 4, we have omitted the Argentine observations identified as anomalous by Lay (1983) (see Table 1) in Figure 5. Different symbols have been used for stations to the east (circles) and to the west (triangles) of the Rocky Mountains. The stations placed in each category are indicated in Table 1 and Figure 1 . Because the station distribution is rather sparse, we do not attempt to define more subregions, although there is ample evidence for distinct behavior for the Pacific Coast stations and Central United States stations. Figure 5 clearly indicates the tendency for western stations, which are slow, to record diminished short-period $S$-wave amplitudes, but the long periods show no regional pattern. The regression curves shown in Figure 5 are given by

$$
\begin{aligned}
& \log A_{S P S}=-0.344( \pm 0.040)-0.042( \pm 0.017) T_{S} \\
& \log A_{L P S}=-0.250( \pm 0.016)-0.001( \pm 0.006) T_{S}
\end{aligned}
$$

The results are not significantly changed if all east coast observations from the Sea of Okhotsk are omitted as well. The short periods have a correlation coefficient of $r=-0.316$, and the long periods yield $r=-0.013$.

The short-period $S$-wave amplitudes in Figure 5 appear to have more of a baseline shift between the eastern and western provinces than a smoothly varying distribution of amplitudes. The filled squares in Figure 5a indicate the average amplitude and travel-time anomalies for each region. There is an amplitude factor of 2.4 and 
a 4.0-sec travel-time shift between the means. Romanowicz and Cara (1980) have shown that if more than one physical parameter varies in the upper mantle (e.g., both velocity and thickness of the low velocity zone), it is possible to have baseline shifts in relative travel-time variations. A similar line of argument applies to $\Delta t^{*}$ variations and, thus, possibly to amplitude variations. To test this, we performed regressions for the short-period $S$-wave amplitudes and station travel-time residuals for the eastern and western provinces separately. The following relations were found;

$$
\begin{aligned}
& \log A_{S P S}=-0.130( \pm 0.053)+0.038( \pm 0.022) T_{S} \text { (east) } \\
& \log A_{S P S}=-0.861( \pm 0.142)+0.118( \pm 0.057) T_{S} \text { (west) }
\end{aligned}
$$

While the absolute levels of these lines are resolvably different, it is interesting to note that the slopes have reversed in sign from that for the overall trend, as have

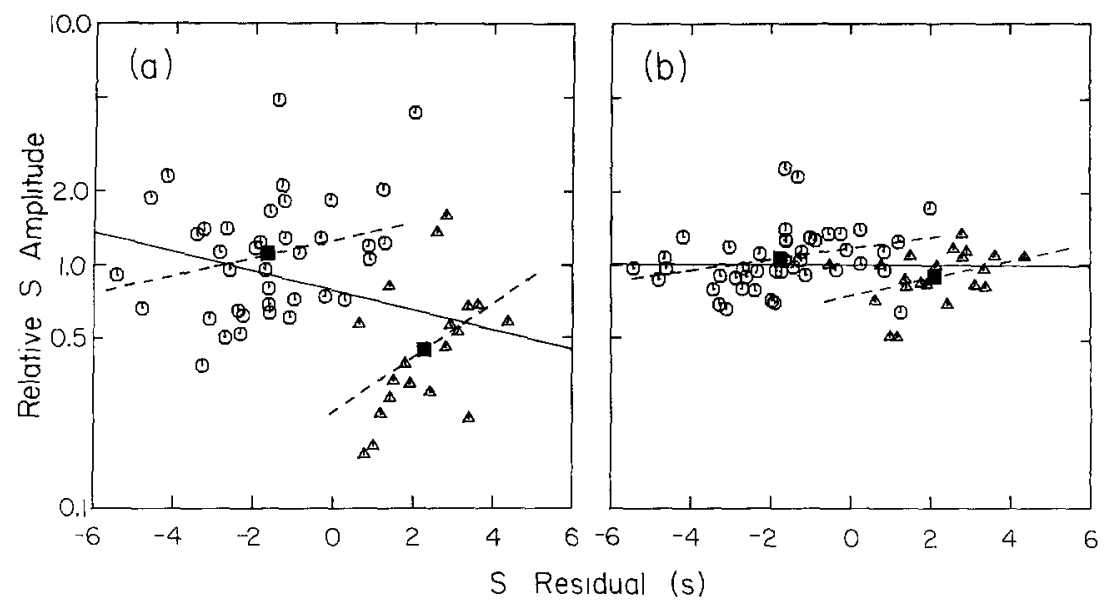

FIG. 5. (a) Comparison of short-period $S$-wave amplitude anomalies and $S$ residuals after anomalous East Coast and Mississippi Valley observations from Argentina are removed. Tectonic province stations are indicated by triangles. The squares indicate the mean travel-time and amplitude values for the eastern and western provinces. The solid curve is a major axis regression for the whole data set, and the dashed curves are for the two provinces separately. (b) Same as in (a) but for the long-period $S$-wave amplitudes.

the corresponding correlation coefficients, $r=0.272$ (east) and $r=0.428$ (west). This may be an artifact of the reduced population sizes and large intrinsic amplitude scatter, however, it may also be taken as a breakdown of the correlation between amplitudes and attenuation if one adopts the assumption that attenuation variations are coupled to velocity variations. There are clearly many scattering and focusing effects that would produce anomalous amplitude behavior with no travel-time signature, or with a correlation opposite to that expected for attenuation variations.

Lay (1983) suggests that the most pronounced long-period amplitude anomalies for the Argentine data are associated with the anomalous travel times produced by lower mantle anomalies, with enhanced amplitudes accompanying large travel-time delays and diminished amplitudes accompanying large travel-time advances. This indicates a geometric effect rather than attenuation-controlled behavior. If the eastern and western long-period data in Figure $5 \mathrm{~b}$ are considered separately, the 
following regressions are found

$$
\begin{aligned}
& \log A_{L P S}=-0.190( \pm 0.026)+0.021( \pm 0.011) T_{S} \text { (east) } \\
& \log A_{L P S}=-0.374( \pm 0.045)+0.035( \pm 0.019) T_{S} \text { (west) }
\end{aligned}
$$

The correlation coefficients are $r=0.289$ (east) and $r=0.381$ (west). This indicates that even after the anomalous Argentine data are omitted, there is a weak tendency for long-period amplitudes to be enhanced for late arrivals, but this is only apparent when the two provinces are isolated. The average long-period amplitude levels in Figure 5b only differ by 18 per cent.

Several authors have noted that while $S$-wave travel-time residuals have an overall variation four times greater than the $P$-wave residuals for North America, the short-period amplitudes have more comparable variations, with $S$ waves varying about twice as much as $P$ waves (Sengupta, 1975; Der et al., 1975, 1982; Lay and Helmberger, 1981). The latter observation is consistent with the trend expected for

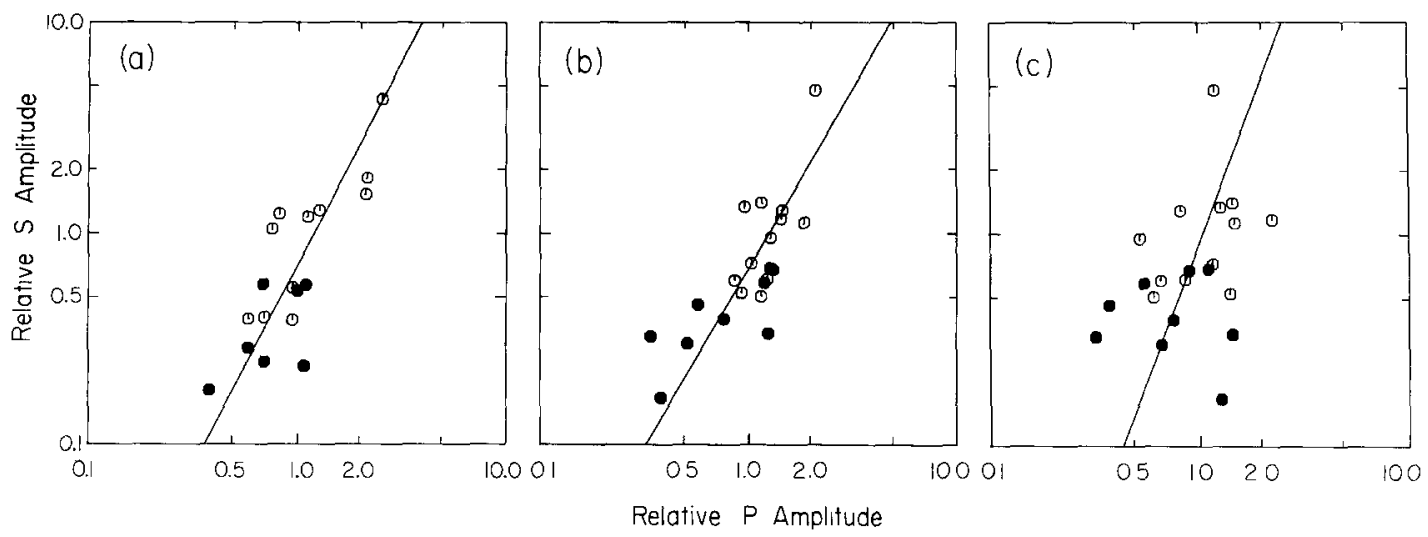

FIG. 6. Comparison between short-period WWSSN $S$ and $P$ amplitude anomalies for (a) South American earthquakes, (b) northwestern azimuth earthquakes, and (c) Sea of Okhotsk earthquakes (S) and Russian nuclear tests (P). Solid symbols indicate Western United States stations.

attenuation-controlled amplitudes for predominantly shear losses (Lay and Helmberger, 1981). The short-period $S$ - and $P$-wave amplitude anomalies are compared in Figure 6. Figure 6a presents the data for South American earthquakes. The regression between the $S$ and $P\left(A_{S P P}\right)$ amplitudes is given by

$$
\log A_{S P S}=-0.397( \pm 0.059)+1.926( \pm 0.338) \log A_{S P P}
$$

This indicates a factor of 2 greater range in the $S$-wave anomalies and a relatively good degree of correlation $(r=0.802)$ for the southern azimuth. For the northwestern azimuth (Figure 6b), a similar relation is found

$$
\log A_{S P S}=-0.414( \pm 0.050)+1.698( \pm 0.310) \log A_{S P P} .
$$

The correlation coefficient is $r=0.767$. In both cases, the amplitude anomalies have been determined for earthquakes spanning a fairly small range in azimuth from each station. Comparison of the $S$ anomalies from the Sea of Okhotsk with the average 
$P$ anomalies from all Russian test sites (which generally span a northern azimuth from each station) shows greater scatter (Figure $6 \mathrm{c}$ ). The corresponding relation is

$$
\log A_{S P S}=-0.292( \pm 0.142)+2.591( \pm 1.581) \log A_{S P P}
$$

This increase in scatter $(r=0.337)$ may reflect the azimuthal sensitivity of the receiver structures beneath the WWSSN stations, or it may indicate the greater variability of amplitude patterns for shallow high-frequency events. The similarity of the relations for the northwestern and southern azimuths argues against the first alternative, whereas Butler and Ruff (1980) have shown that amplitude patterns for explosions at sites in as close a proximity as northern and southern Novaya Zemlya can have significant relative trends. This may be due to near-source structure or contamination due to tectonic release.

Lay and Helmberger (1981) have shown that long-period $P$ and $S H$ amplitude patterns from South America track rather closely as well, with relative variations being consistent with attenuation variations assuming all losses are in shear. However, the long-period amplitude variations are so large that explaining them by frequency-independent $Q$ variations predicts short-period amplitude patterns that are poorly correlated with and have a larger range than those observed. While frequency-dependent models can be contrived to reconcile the data, there is little correlation with geographic province or travel-time anomalies. This indicates that receiver structure or propagational effects dominate the long-period amplitudes, as was proposed by Booth et al. (1974), and it is possible that part of the correlation in short-period amplitudes for $P$ and $S H$ is produced by receiver variations as well. Computation of amplification effects for plane-layered receiver structures using the Haskell matrix techniques indicates that relative short-period $P$ - and $S$-wave amplitudes can track closely for a wide range of models. It is also interesting to note that $\Delta t^{*}$ estimates made from long-period body-wave spectra do not accurately predict short- or long-period amplitude variations for North America (Lay and Helmberger, 1981), nor are they well correlated with short-period travel-time anomalies on a global scale (Mikami and Hirahara, 1981). This may suggest that the $\Delta t^{*}$ estimates at long periods are contaminated by three-dimensional receiver structure or other effects not related to upper mantle attenuation.

The correlations shown previously between short-period $S$ amplitudes and travel times and short-period $P$ and $S$ amplitudes predict a correlation between $P$ amplitudes and $S$ travel times. This is, in fact, observed as shown in Figure 7 . The $P$ amplitude anomalies from the northwestern azimuth are compared with the $S$ travel times from the Sea of Okhotsk, with the relation between them being

$$
\log A_{S P P}=-0.001( \pm 0.043)-0.026( \pm 0.017) T_{S}
$$

A value of $r=-0.318$ was found for this comparison. Once again, it appears that a step-like shift in the amplitude level between the fast eastern (circles) and slow western (triangles) provinces is an equally valid interpretation.

Numerous studies have found that North America $S$-wave travel-time anomalies are roughly four times the corresponding $P$-wave anomalies (Doyle and Hales, 1967; Hales and Roberts, 1970; Sengupta, 1975). This requires upper mantle variations preferentially affecting the rigidity (Hales and Doyle, 1967; Hales and Herrin, 1972). On a global basis, the relation between $S$ and $P$ anomalies appears to be different from that for North America, with a relative factor of 1.8 to 2.4, which does not 
require significant lateral variations in Poisson's ratio (Poupinet, 1977; Wickens and Buchbinder, 1980). It has also been proposed that the relation for North America has been misinterpreted if more than one physical parameter varies in the upper mantle (Romanowicz and Cara, 1980).

In Figure 8, we compare the $S$-wave travel-time residuals from the Sea of Okhotsk and Argentina with the azimuthally dependent $P$-wave station anomalies $\left(T_{P}\right)$ of Dziewonski and Anderson (1982), which have the form

$$
T_{P}=A+B \cos \left(\phi-\phi_{1}\right)+C \cos \left[2\left(\phi-\phi_{2}\right)\right] \text {. }
$$

The azimuths, $\phi$, used to compute the $P$ residuals are the appropriate azimuths from each station to the Sea of Okhotsk and Argentine source regions. Figure 8, a to c, shows the northwestern azimuth comparison, with the first panel using the azimuthally independent term (A) of the $P$ residual only; the second including the $\cos \phi$ term; and the third including the $\cos 2 \phi$ term as well. Since not all five coefficients

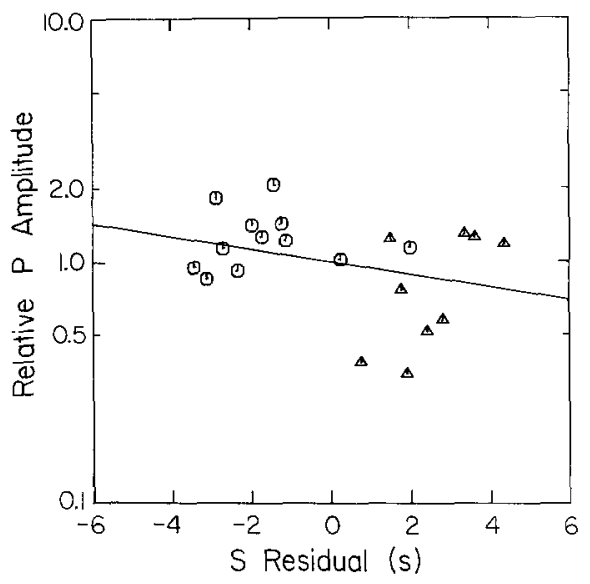

Fig. 7. Comparison between $P$-wave amplitude anomalies and $S$-wave travel-time residuals for the northwestern azimuth. Triangles indicate western North America stations.

could be determined for each station, there is a slight attrition as higher order terms are added. However, this does not account for the significant reduction in scatter of the correlations as the azimuthal terms are included $(r=0.45,0.62$, and 0.77 in Figure 8 , a to c, respectively). The value of the slope given by the major axis regression is indicated in each panel. Stations in western North America are indicated by triangles. Note that these are slow for both $P$ and $S$, and there is little overlap between the provinces. The slope in Figure $8 \mathrm{c}$ is somewhat higher than the typical value of approximately 4 , and the small scatter indicates that this may be significant. The lower value has always been determined using azimuthally averaged data, which may have resulted in an underestimation of the relative behavior, or it may be that the Sea of Okhotsk source region and/or lower mantle path effects account for the discrepancy.

The Argentine comparisons are shown in Figure 8, $\mathrm{d}$ to $\mathrm{f}$. Here, the reduction in number of stations with higher order $P$ anomaly azimuthal terms is more severe, but there is again some indication that a slope significantly higher than 4 may be appropriate ( $r=0.45,0.45$, and 0.68 in Figure $8, \mathrm{~d}$ to $\mathrm{f}$, respectively). The separation between the eastern and western provinces is not as clear as for the other azimuth, 
which results from the anomalous $S$ and $P$ travel-time anomalies that affect the east coast stations. The azimuthal variations are similar for both $P$ and $S$ for the latter stations, and are too strong to be produced at shallow depth in the upper mantle. It is likely that some of the lower mantle path anomaly detected in the $S$ waves by Lay (1983) has been mapped into the $P$-wave station anomalies for the southern azimuth. For both azimuths, the correspondence between $P$ and $S$ traveltime anomalies is quite good, and there is little evidence for a baseline shift and decreased slope between the eastern and western provinces like those indicated by Romanowicz and Cara (1980). The importance of azimuthal terms in the station anomalies is strongly supported by these data.

\section{Discussion}

By determining the relationships between travel-time residuals, amplitude anomalies, and attenuation variations, it will ultimately be possible to constrain some important upper mantle processes, following approaches similar to that first em-
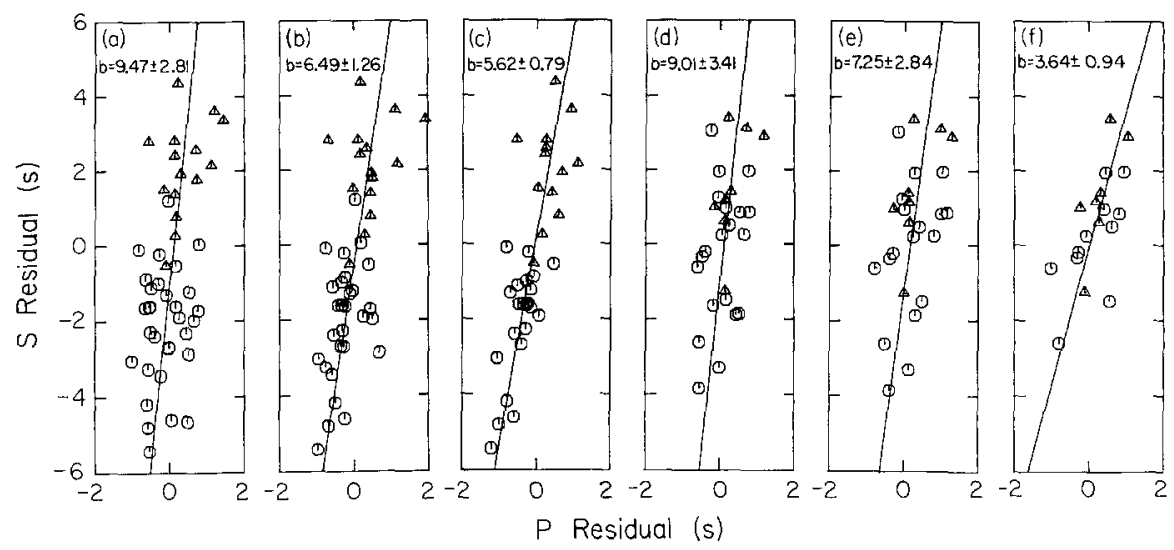

Fig. 8. $S$ and $P$ travel-time residuals from the Sea of Okhotsk azimuth (a) to (c) and the Argentina azimuth (d) to (f). The $P$-wave station anomalies of Dziewonski and Anderson (1982) are used with the azimuthally independent term alone (a) and (d); inclusion of the first $\cos \phi$ term (b) and (e); and inclusion of both the $\cos \phi$ and $\cos 2 \phi$ terms (c) and (f). The value of the slope in the regression $T_{S}=a+b T_{P}$ is given for each panel. Triangles indicate stations in the western tectonic province.

ployed by Solomon (1972). This paper has shown that there is a clear, although weak, correlation between short-period $P$ - and $S$-amplitude anomalies and $S$-wave travel-time residuals. In general, western North America records low amplitudes and late arrivals relative to the east. While this result is qualitatively consistent with many previous studies, it is the first to compare a large data set of short-period $S$ amplitudes and travel times obtained from the same signals with $P$ amplitudes that are similarly processed.

It is strongly indicated that a step-like change in amplitude level occurs across the Rocky Mountain front, with amplitudes within the eastern and western provinces being poorly correlated with travel-time variations. The step between the average short-period $S$-wave amplitude levels is a factor of 2.4 , which approximately corresponds to a $\Delta t_{\beta}^{*}=0.8 \mathrm{sec}$ for the 2- to 4 -sec periods of the observations (Lay and Helmberger, 1981). Assuming all losses in shear, this indicates $\Delta t_{\alpha}^{*}=0.2 \mathrm{sec}$, which produces a factor of 2 variation in amplitude at 1 -sec period. This is consistent with the average $\Delta m_{b}(0.26)$ value between the provinces (Booth et al., 1974; Der et $a l ., 1975)$ and with average differences in $\Delta t_{\alpha}^{*}$ from high-frequency spectral analysis 
(Der et al., 1982). The long-period $S$-wave amplitude variation predicted for $\Delta t_{\beta}^{*}=$ $0.8 \mathrm{sec}$ is about 20 per cent (Lay and Helmberger, 1981), which is consistent with the 18 per cent variation found in Figure $5 \mathrm{~b}$. The associated $S$-wave travel-time step is about $4 \mathrm{sec}$. Superimposed on this attenuation-controlled amplitude variation are many individual station variations that are not associated with travel-time anomalies and presumably reflect receiver structure or scattering effects within the mantle. These amplitude variations are comparable to those produced by attenuation variations. The long-period $S H$-wave amplitudes show no overall correlation with travel-time anomalies, although within each province there is a tendency for later arrivals to be enhanced, thus it is probable that receiver structure or other propagation effects are responsible for much of the substantial variation in long-period amplitudes. There is recent work using body waves that shows that lateral variations in upper mantle shear velocity structure beneath North America are distributed throughout the upper mantle to a depth of $400 \mathrm{~km}$ (Grand and Helmberger, in preparation, 1983). Future work with body waves will be needed to determine whether the variations in $Q$ are similarly distributed or concentrated in a narrow channel.

The relative variation of $S$ and $P$ residuals may have a steeper slope than previously found in studies which neglect the azimuthal variations in station anomaly terms. If this proves generally valid, even more dramatic variations in rigidity in the upper mantle are required, or possibly alternate mechanisms such as anisotropy.

\section{ACKNOWLEDGMENTS}

This research was supported in part by the National Science Foundation under Grant NSF EAR 8108616 and by the Advanced Research Projects Agency of the Department of Defense. This research was also monitored by the Air Force Office of Scientific Research under Contract F49620-81-C-0008.

\section{REFERENCES}

Booth, D. C., P. D. Marshall, and J. B. Young (1974). Long and short period $P$-wave amplitudes from earthquakes in the range $0^{\circ}-114^{\circ}$, Geophys. J. Roy. Astr. Soc. 39, 523-537.

Butler, R. and L. Ruff (1980). Teleseismic short-period amplitudes: source and receiver variations, Bull. Seism. Soc. Am. 70, 831-850.

Butler, R., L. J. Ruff, R. S. Hart, and G. R. Mellman (1979). Seismic waveform analysis of underground nuclear explosions, Technical Report, SGI-R-79-011.

Cleary, J. (1967). Analysis of the amplitudes of short-period $P$-waves recorded by Long Range Seismic Measurements stations in the distance range $30^{\circ}$ to $102^{\circ}, J$. Geophys. Res. 72, 4705-4712.

Der, Z. A. and T. W. MeElfresh (1977). The relationship between anelastic attenuation and regional amplitude anomalies of short-period $P$-waves in North America, Bull. Seism. Soc. Am. 67, 1303-1317.

Der, Z. A., R. P. Massé, and J. P. Gurski (1975). Regional attenuation of short-period $P$ - and $S$-waves in the United States, Geophys. J. Roy. Astr. Soc. 40, 85-106.

Der, Z. A., T. W. McElfresh, and C. P. Mrazek (1979). Interpretation of short-period $P$-wave magnitude anomalies of selected LRSM stations, Bull. Seism. Soc. Am. 69, 1149-1160.

Der, Z. A., T. W. McElfresh, and A. O'Donnell (1982). An investigation of the regional variations and frequency dependence of anelastic attenuation in the mantle under the United States in the 0.5-4.0 Hz band, Geophys. I. Roy. Astr. Soc. 69, 67-99.

Doyle, H. A. and A. L. Hales (1967). An analysis of the travel times of $S$-waves to North American stations, in the distance range $28^{\circ}$ to $82^{\circ}$, Bull. Seism. Soc. Am. 57, 761-771.

Dziewonski, A. M. and D. L. Anderson (1983). Travel times and station corrections for $P$-waves at teleseismic distances, J. Geophys. Res. 88, 3295-3314.

Evernden, J. F. and D. M. Clark (1970). Study of teleseismic P II-amplitude data, Phys. Earth Planet. Interiors 4, 24-31.

Hales, A. L. and H. A. Doyle (1967). $P$ and $S$ travel time anomalies and their interpretation, Geophys. J. Roy. Astr. Soc. 13, 403-415. 
Hales, A. L. and J. L. Roberts (1970). The travel times of S and SKS, Bull. Seism. Soc. Am. 60, 461-489.

Hales, A. L. and E. Herrin (1972). Travel Times of Seismic Waves in Nature of the Solid Earth, E. C. Robertson, McGraw-Hill, New York, 172-215.

Hales, A. L., J. R. Cleary, H. A. Doyle, R. Green, and J. Robert (1968). P-wave station anomalies and the structure of the upper mantle, J. Geophys. Res. 73, 3885-3896.

Herrin, E. and J. Taggart (1962). Regional variations in $P n$ velocity and their effect on the location of epicenters, Bull. Seism. Soc. Am. 52, 1037-1046.

Lay, T. (1983). Localized velocity anomalies in the lower mantle, Geophys. J. Roy. Astr. Soc. 72, 483-516.

Lay, T. and D. V. Helmberger (1981). Body wave amplitude patterns and upper mantle attenuation variations across North America, Geophys. J. Roy. Astr. Soc. 66, 691-726.

Mikami, N. and K. Hirahara (1981). Global distribution of long-period $P$-wave attenuation and its tectonic implications, J. Phys. Earth 29, 97-117.

North, R. G. (1977). Station magnitude bias: its determination causes and effects, Report No. ESD-TR77-85, Lincoln Laboratory, Lexington, Massachusetts.

Poupinet, G. (1977). Heterogeneities du manteau terrestre deduites de la propagation des ondes de volume: implication geodynamique, Thèse présentée à l'Université Scientifique et Médicale de Grenoble, Grenoble, France.

Romanowicz, B. A. and M. Cara (1980). Reconsideration of the relations between S and P station anomalies in North America, Geophys. Res. Letters 7, 417-420.

Romney, C., B. C. Brooks, R. H. Mansfield, D. S. Carter, J. N. Jordan, and D. W. Gordon (1962). Travel times and amplitudes of principal body phases recorded from Gnome, Bull. Seism. Soc. Am. 52, 1057-1074.

Sengupta, M. K. (1975). The structure of the earth's mantle from body wave observations, M.S. Thesis, Massachusetts Institute of Technology, Cambridge, Massachusetts, $578 \mathrm{pp}$.

Shore, M. J. (1982). Seismic travel-time anomalies from events in the western Soviet Union, Bull. Seism. Soc. Am. 72, 113-128.

Solomon, S. C. (1972). Seismic wave attenuation and partial melting in the upper mantle of North America, J. Geophys. Res. 77, 1483-1502.

Wickens, A. J. and G. G. R. Buchbinder (1980). S-wave residuals in Canada, Bull. Seism. Soc. Am. 70, $809-822$.

York, D. (1966). Least-squares fitting of a straight line, Canadian J. Phys. 44, 1079-1086.

Seismological Laboratory

California Institute of Technology

Pasadena, California 91125

Contribution No. 3852

Manuscript received 3 December 1982 